\section{Review: antidepressants plus benzodiazepines lead to fewer dropouts and less depression severity at 4 weeks in major depression}

Furukawa T, Streiner DL, Young LT. Antidepressant plus benzodiazepine for major depression. Cochrane Database Syst Rev 2000;(4):CD001026 (latest version 29 Aug 2000).

QUESTION: In adults with major depression, does combination treatment with antidepressants and benzodiazepines lead to any benefits in terms of short term ( $<8 \mathrm{wks}$ ) or long term ( $>2 \mathrm{mo}$ ) symptomatic recovery or side effects?
Sources of funding: Ministry of Health and Welfare,Japan; Uehara Memorial Foundation, Japan.

For correspondence: Professor T Furukawa Department of

Psychiatry, Nagoya City University, School of Medicine, Mizuho-cho Mizuho-ku Aichi Nagoya,Japan, 467 8601.Fax +8152852 0837.

\section{Data sources}

Studies were identified by searching Medline, EMBASE/ Excerpta Medica, International Pharmaceutical Abstracts, Biological Abstracts, LILACS, PsycLIT, the Cochrane Library, and the trial register of the Cochrane Depression, Anxiety and Neurosis Group (January 1972 to December 1998); handsearching major mental health and general medicine journals; scanning the reference lists of identified articles; checking SciSearch; and by personal contacts.

\section{Study selection}

Studies were selected if they were randomised controlled trials comparing combined antidepressant-benzodiazepine treatment with antidepressants alone in adults with major depression. Studies were excluded if the antidepressant dose was $<100 \mathrm{mg}$ of imipramine or its equivalent daily or the duration of the trial was $<4$ weeks.

\section{Data extraction}

Data were extracted on patient characteristics, treatment type and dose, duration of follow up, and main outcomes.

\section{Main results}

9 studies involving 679 patients met the selection criteria. The antidepressants studied were imipramine, desipramine, amitriptyline, maprotiline, nortriptyline, clomipramine, fluoxetine, and mianserin; benzodiazepines studied included triazolam, alprazolam, diazepam, chlordiazepoxide, flunitrazepam, lormetazepam, bentazepam, clonazepam, and mexazolam. Patients allocated to the combined treatment group were less likely to drop out of the study than those in the antidepressant alone group (table). These patients were also less likely to drop out due to side effects (table). More patients in the combined treatment group showed a $>50 \%$ reduction from their baseline depression severity at 4 weeks than those in the antidepressant alone group (worst case scenario for dropouts, table ). This difference was no longer statistically significant at 8 weeks.

\section{Conclusion}

In adults with major depression, a combination of antidepressant and benzodiazepine treatment leads to fewer dropouts and less depression severity at 4 weeks than antidepressants alone.
Combined antidepressant and benzodiazepine treatment $v$ antidepressant alone in adults with major depression*

\begin{tabular}{|c|c|c|c|c|}
\hline \multirow[b]{2}{*}{ Outcomes } & \multicolumn{2}{|c|}{ Weighted event rates } & \multirow[b]{2}{*}{$\operatorname{RRR}(95 \% \mathrm{Cl})$} & \multirow[b]{2}{*}{ NNT (CI) } \\
\hline & Combined & $\begin{array}{l}\text { Antidepressant } \\
\text { alone }\end{array}$ & & \\
\hline Dropped out & $22 \%$ & $33 \%$ & $37 \%(19$ to 51$)$ & 10 (6 to 22$)$ \\
\hline \multirow[t]{2}{*}{$\begin{array}{c}\text { Dropped out due } \\
\text { to side effects }\end{array}$} & $7 \%$ & $14 \%$ & $48 \%$ (14 to 68$)$ & 15 (10 to 40$)$ \\
\hline & Combined & $\begin{array}{l}\text { Antidepressant } \\
\text { alone }\end{array}$ & $\mathrm{RBI}(\mathrm{Cl})$ & NNT (CI) \\
\hline $\begin{array}{l}>50 \% \text { reduction in } \\
\text { depression at } 4 \\
\text { weeks }\end{array}$ & $52 \%$ & $37 \%$ & $38 \%(15$ to 66$)$ & 7 (5 to 15$)$ \\
\hline
\end{tabular}

*Abbreviations defined in glossary; RRR, RBI, NNT, and $\mathrm{Cl}$ calculated from data in article.

\section{COMMENTARY}

This valid review by Furukawa et al shows that benzodiazepines may add to the efficacy of antidepressants. The effect is strongest after 1 week, lasts until 4 weeks, and disappears after $6-8$ weeks, although this latter finding is based on only 162 patients.

What could cause this somewhat unexpected benefit? Firstly, it may be that benzodiazepines prevent the occurrence of anxiety related adverse effects in the first weeks of treatment. This may have lead to fewer dropouts particularly in the studies with selective serotonin reuptake inhibitors (SSRIs). The 2 studies (126 patients) evaluating SSRIs do not seem to exclude such a trend, but no subgroup analysis was done. The effect, however, is still statistically significant after exclusion of dropouts.

Secondly, the beneficial effect may be due to a reduction of anxiety and sleep disturbance, leaving the core symptoms of low mood and anhedonia undisturbed. Such a subgroup analysis was not possible and would require collection of individual patient data. Reduction in anxiety, however, could very well also speed up or promote further remission, or both.

Finally, a true additional effect of benzodiazepines would be in accordance with the increasing evidence for low gamma-aminobutyric acid function in depression. ${ }^{1}$ The possible earlier onset of action is intriguing in this respect, because this is exactly what pharmaceutical companies have been looking for in new drugs without much success.

What are the clinical consequences? Clinicians are advised to prescribe benzodiazepines only to patients with severe anxiety and for no longer than $2-4$ weeks. This review offers support for the not uncommon practice to combine antidepressants with benzodiazepines for depressed patients that have severe symptoms of anxiety who develop these on antidepressants. They should preferably be prescribed during the first weeks only and be withdrawn gradually: the only 2 studies in this review that investigated the risk of relapse after withdrawal reported numbers needed to harm of 2 and 7 .

Harm Gijsman, MD University of Oxford Oxford, UK

1 Shiah I-S, Yatham LN. GABA function in mood disorders: an update and critical review. Life Sci 1998;63:1289-303. 